DOI: https://doi.org/10.34069/AI/2021.45.09.9

How to Cite:

Kundi, G.M. (2021). Relationship between quality of work-life and individual work performance: Moderating role of organizational culture. Amazonia Investiga, 10(45), 88-98. https://doi.org/10.34069/AI/2021.45.09.9

\title{
Relationship between quality of work-life and individual work performance: Moderating role of organizational culture
}

\author{
العلاقة بين جودة العياة العملية وأداء العمل الفردي: دور الوسيط للثقافة التنظيمية
}

Received: August 15, 2021

Accepted: September 25, 2021

Written by:

Ghulam Muhammad Kundi

https://orcid.org/0000-0003-3082-1611

\begin{abstract}
The study aimed to find the contingent role of organizational culture upon relation and cooperation, and facilities provided to employees at the workplace to enhance individual's work performance. A crosssurvey approach was adopted. A total of 400 complete questionnaires were used in the analysis. SPSS-25 was used for the analysis of data. Hierarchical multiple regression was employed to test the hypotheses. It was found that there is a significant moderating role of organizational culture upon relation and cooperation, and facilities provided to employees to enhance individual work performance. The study finds that there is an intense need to improve the quality of work-life and workplace of health professionals so they deliver their best to achieve organizational objectives. The study recommends that there is a need to a supportive culture because it plays an instrumental role in bringing the desired level of performance which ultimately leads the organization to success. This study was conducted in healthcare organizations; the findings of this study could only be generalized into the health sector.
\end{abstract}

Keywords: Facilities, Individual Work Performance, Organizational Culture, Quality of Work-Life.

هدفت الدراسة إلى معرفة الدور العرضي للتقافة التنظيمية على العلاقة والتعاون ، و التسهيلات المقدمة للموظفين في مكان العمل لتعزيز

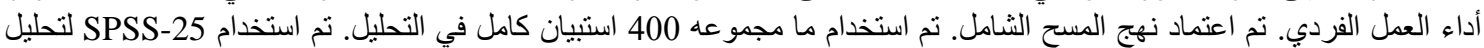

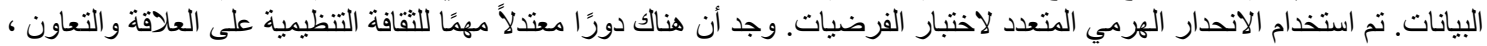

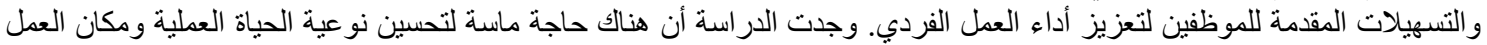

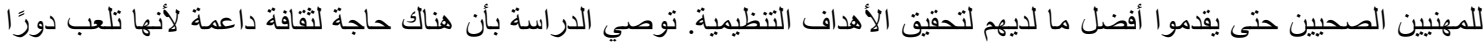

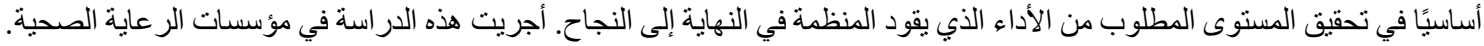

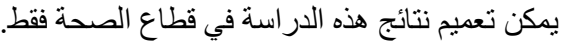

لكلمات المفتاحية: جودة الحياة العملية ، المر افق ، الثقافة التنظيمية، أداء العمل الفردي.

\section{Introduction}

Previously, the words happiness, well-being, and health were used to denote "quality of life" but these terms are now obsolete and have several problems while defining them in an absolute terminology since people were defining and using them with varying meanings on different occasions. Therefore, these words were substituted by a more comprehensive and absolute concept of "quality of work-life". The concept was first coined by Pigou in 1920 in his book "Economic Well-being". Initially, this book was overlooked and constantly ignored till the end of World War II. After WWII, World Health Organization (WHO) further refined, redefined, and expanded the concept of health where social wellbeing was included in the definition of health inter alia the physical and psychological concepts. Then after WHO popularized the new

Department of Health Administration, College of Public Health and Health Informatics, Al-Bukayriyah Qassim University, Kingdom of Saudi Arabia. 


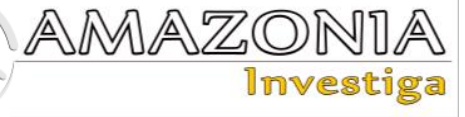

definition of quality of work-life (QWL) as an aim of individuals aligned with cultural and values system linked with hopes, living standards, and interests (Allworth, \& Hesketh, 1999). This definition includes the physical, psychological, and social well-being of an individual, that how an individual makes relations with surroundings, and their level of independence, etc. The concept of quality of work-life got the attention of researchers, academicians, and practitioners since mid of the last century (Ruzevicius, 2012). Previously quality of work-life and quality of life was considered as material welfare and wealth but later on the concept of values was also added into the definition of quality of life and work-life thus, the concepts were modified. Based on those new models, theories, and instruments were developed by the researchers to measure the quality of work life. The quality of life was studied in the past studies, even still the life at the workplace was overlooked in these studies. This study is an effort to fill the gaps in the theories and models of quality of work-life (Ashford, 1986). The study is conducted to investigate the contingent role of organizational culture upon relation and cooperation, and facilities provided to employees at the workplace to enhance individual's work performance.

\section{Literature Review}

Theoretical Framework Analysis (TFA) was employed to review the existing sources of literature related to the relationship between quality of work-life (QWL), individual work performance (IWP), and organizational culture (OC) which suggest the use of several qualitative analysis models like: 'thematic network analysis' by Attride-Stirling (2001); 'Grounded-theory' of Glasser \& Strauss (1967), 'Framework-Analysis' by Ritchie \& Spencer (1994).

\section{Quality of work-life}

Quality of work life is linked with organizational practices, it deals with enhancing a professional's mental health, satisfaction, and safety. An increase in quality of work-life ensures the retention of a highly productive workforce (Almalki, Fitzgerald, \& Clark, 2012). The increasing complexities and challenges at the workplace greatly influenced individual work performance, for example, awareness and knowledge management, rapid technology change is making the work environment more complex and difficult (Taher, 2013). With emerging challenges and complexities, health professionals are facing several issues related to the quality of work-life, due to lack of satisfaction, the individual work performance in healthcare organizations has recorded a decrease in their performance (Albejaidi, Kundi, \& Mughal, 2020).

In this study, the researcher used quality of worklife as a predictor. Sirgy et al. (2001) have categorized quality of work-life into two groups i.e., higher-order needs and lower-order needs. According to them, higher-order needs included self-esteem, self-actualization, and aesthetic needs, while lower-order needs consist of safety, health, and wellbeing, etc. Later on, Zare et al. (2012) divided quality of work-life into four main attributes such as work-life balance, social factors, economic factors, and job content factors. Work-life balance includes fair and flexible working hours, permission to perform religious activities, the distance between personal life and work life. While social factors include social integration, social networking, respect to employees, self-esteem needs, likewise, economic factors include health, salary, job satisfaction, wellbeing, insurance, health services, and retirement, etc. Similarly, job content factors include teamwork, training and development, career growth, proper work environment, facilities, autonomy at work, and interpersonal relationship with colleagues and supervisors, etc. (Malik, Cao, Mughal, Kundi, Mughal, \& Ramayah, 2020; Awan et al., 2014).

Before this model, Hsu and Kernohan (2006) categorized the quality of the work-life model into 56 attributes with six main themes. These themes are demography, organizational aspect, socio-economic aspects, self-actualization, work aspect, and human relation aspect. In addition, Deb (2006) divided quality of work-life into job rotation, career development, job enrichment, and participation in the decision-making process. Based on the above discussion, this study used work environment, relation and cooperation, training and development, facilities, job satisfaction, autonomy at work, salary, and facilities as predictors of individual work performance. On the other side, individual work performance was taken as criterion variables in the study. Azril et al. (2010) claimed a very weak relationship between quality of work-life and individual work performance, thus, there was an immense need to add some contingent variable.

\section{Relation and Cooperation}

Every employee and every manager in one way or the other are involved in some kind of relationship in work settings. The relationship 
and cooperation with each other are sometimes positive and productive, while sometimes, it is negative when influenced by nepotism, favoritism, and cynical behavior, etc. is practiced. People work individually as well as collectively in groups to achieve some common goals and objectives, the hallmark of management Zare et al. (2012). A manager is given authority and control over the resources. By using these two things, they get the work done by working with or working through the employees through command and direction to complete a specified task. A manager alone is unable to complete the task, therefore, s (he) uses human resources, here good and intimate relations between leaders and followers become significant and instrumental for managerial success and enhanced performance (Akhtar, Nazarudin, \& Kundi, 2021a). Hsu and Kernohan (2006) asserts that their cooperation with each other in form of sharing knowledge, information and extending help to each other help the organization materializes its goals through timely completion of the assigned tasks. Babalola, Gbadegesin, \& Patience, (2014) have reported that usually, this relation falls under the vertical category i.e., from manager-to-subordinate, also called superior-subordinate relationship, or master-servant relationship. The manager is responsible to identify, control and rectify the mistakes of employees at the workplace through timely directions and guidance. And this is possible only if effective communication is employed, therefore, (Albejaidi, Kundi, \& Mughal, 2020). considered effective communication skills as a prerequisite for good and efficient management. Some managers have direct communication with their subordinates while others create power distance, both create a unique mindset among the employees in the organizations.

The concept of the subordinate-supervisor relationship is deeply rooted in the concept of leadership styles. Leadership is the process, and a leader is a person who can motivate their employees. A leader can come up with novel ideas and instill those ideas in each member of the team and motivate and satisfy them, cooperate with them to achieve their personal as well as organizational goals (Malik, Cao, Mughal, Kundi, Mughal, \& Ramayah, 2020; Awan et al., 2014). According to Babalola et al (2014), there are four dimensions of superiorsubordinate communication relationship, i.e., positive communication relationship, upward openness communication, negative, and jobrelated communication. The positive relationship communication allows the employees to send feedback and queries about work in the organizations to the managers.

Managers are open to take feedback from employees, listen to their problems, solve them, and help them to participate in the decisionmaking process (Akhtar, Nazarudin, \& Kundi, 2021b). While upward communication relationship allows the employees to agree and disagree with their manager/supervisor. Negative relationship communication is used by those managers who do not leave any opportunity to criticize the employees, likewise, job-related relationships and communication include information, rules, policies, and supervisor feedback about the performance (Babalola, Gbadegesin, \& Patience, 2014). Those leaders which allow their employees to participate in the decision-making process, listen to them, and help them to progress in their career are considered the most effective leaders, this kind of relationship and cooperation with employees falls under the category of transformational leadership styles.

\section{Facilities}

According to Asmui, Hussin, and Paino (2012) facilities influence the mental and physical capabilities of the workforce. Healthy workplace such as human-centric office design, arrangement of furniture, state-of-the-art equipment, and provision of internet, $\mathrm{Wi}-\mathrm{Fi}$, pleasant lighting arrangement, stationery, and other facilities increase the productivity of employees. It is found that proper provision of needed facilities can reduce the level of physical and mental stress among the employees. They also argued that if organizations lack such facilities as a result it will increase safety issues, which also include stress, absenteeism, and decreased productivity. Work stress is defined as harmful emotional and physical responses, and it occurs when job facilities do not match the potential and capabilities of the employees. Facilities deals with ergonomics, while the poor practice of ergonomics will lead to poor performance, thus, to deliver at their best, it is essential to facilitate the employees with the best working environment, conditions, and facilities. An appropriate and comfortable human-centered working environment and facilities help the organizations to achieve the desired level of performance (Akhtar, Nazarudin, \& Kundi, $2021 \mathrm{ab}$ ). The nonalignment between human needs and facilities will lead to work-related musculoskeletal disorders. Daubermann et al. (2011) have reported 12 twelve ergonomics principles to be followed by a health organization 


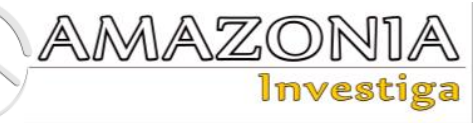

to achieve the desired level of employee performance against the standard and criteria. These principles are (1). everything easy to reach, (2) proper heights for work, (3) excessive force must be reduced, (4) work in good postures, (5) repetition must be reduced, (6) reduce fatigue, (7) pressure on employees must be reduced, (8) allow the employees to get adjusted to the environment, (9) clearance and access, (10) provide a comfortable work environment, (11) improve understanding, (12) work organization must be improved. Furthermore, the physical work environment includes chairs, lighting, working hours, and humidity, etc.

\section{Individual Work Performance (IWP)}

Individual work performance is an issue that has exclusively keep the organizations worried throughout the world, attracted the researchers to put efforts to investigate the issues faced by management related to wellbeing and employee performance. Various studies on individual work performance have been conducted with diverse methodologies on work, commitment, fulfillment, and identity of individual work performance (Koopmans, Bernaards, Hildebrandt, Schaufeli, de Vet Henrica, \& van der Beek, 2011. However, literature is replete with varying approaches to study an individual work performance and to make the individual as productive as possible, likewise, organizational psychologists studied the influence of work engagement, satisfaction, and personality on the individual work performance in healthcare organizations. It is reported that individual work performance differs from job to job, therefore numerous measures have been used for the individual work performance measurement (Koopmans, Bernaards, Hildebrandt, Schaufeli, de Vet Henrica, \& van der Beek (2011). Since work performance is a latent abstract construct that could not directly be measured, therefore, it is measured against its dimensions (Fay \& Sonnentag, 2009). The universally accepted definition of work states that it is the behavior or action related to the objectives of an organization (Lennox \& Mansfield 2011). The employee work performance is distinct from the productivity of work, whereas work productivity implies an input divided by output, which means that work performance is a broader concept than work productivity.

\section{Organizational Culture}

Hofstede (1997) defined culture as values, beliefs, traditions of the society, organizations, or group of people and it plays a significant role in the success of any organization for which organizations needs culture must support the business. The internal stakeholders, their values, belief, and traditions greatly influence the decision-making process (Acar \& Acar, 2014). According to Zeqiri and Alija (2016) culture also has subcultures since all stakeholders come from different backgrounds, i.e., doctors might belong to cultures, where nurses come from other cultures, and the paramedical staff from another culture, once all these cultural differences met at one place they influence the overall culture of the organization in their way (Malik, Cao, Mughal, Kundi, Mughal, \& Ramayah, 2020). Anthropologists consider culture as rituals and customs, according to Zare et al. (2012), culture is a set of beliefs, values, norms, and assumptions that change the behavior of individuals, teams, groups in the organizations (Gatseliuk, Strelbitska, Herasymchuk, Pavlyshyn, \& Khrystiuk, 2021). Hofstede (1997) defined culture as the programming of the mind which distinguishes one group different from another group. Organizations are made up of individuals and groups who share some common values and develop their own culture. Hofstede (1997) developed a model of organizational culture with six dimensions, which is widely considered by the researchers as a reliable and authentic model to understand the organizational culture. All studies point that culture plays a significant moderating role between the quality of work-life and individual work performance (Awadh \& Saad, 2013).

\section{Relationship between Quality of Work-life, Individual Work Performance, and Organizational Culture}

The theory of social exchange states an exchange is the trade of tangible and intangible activities that could be rewarding or non-rewarding between at least it involves two persons i.e., one is party ' $A$ ', and second is party ' $B$ '. Social exchange behavior describes that behavior of ' $A$ ' weakens or strengthens the behavior of ' $\mathrm{B}$ '. Cropanzano et al. (2017) state that this relationship is based on reciprocal gains and benefits, thus, in such a relationship, one party might repay the good or bad deeds at the cost of the other. Based on these notions therefore researcher has based this study on the social exchange theory recommended by (Bligh, 2017; Busari et al., 2019). The organizational culture moderates relationship between quality of worklife and enhance individual work performance. Cameron and Quinn employed the theory of membership reaction in observing organizational culture and argued that a positive relationship 
exists between the quality of work-life and individual work performance (Akhtar, Nazarudin, \& Kundi, 2021a).

Quality of work-life has the power to influence the feelings and individual performance of an employee in an organization. Studies enlist several factors that determine the quality of the work-life process of an employee like, the fair and adequate financial and fringe benefits, and opportunity for professional growth and development, etc. (Wahlberg, Ramalho, \& Brochado, 2017). The relations between quality of work-life, and employee performance were studied by were Kanten and Sadullah (2012) they analyzed the consistency of the instrument that evaluates the quality of work-life. Similarly, a study by Warrick (2017) found that to develop a corporate organizational culture needs cooperation, which requires the development of leaders who undertake quality of work-life as a vital task with understanding to the aligning organization decision making with the cultural ideals. Warrick (2017) reported the relationship between organizational culture and components of quality of work-life on employee the health and safety of the workplace. Valizadeh and Ghahremani (2012) have found a direct and significant relationship between the quality of employees' work-life and organizational culture.

Awadh and Saad (2013) investigated the influence of organizational culture on employee performance and found that it is a significant predictor of job effectiveness. Furthermore, Kwahar \& Akuraun (2018). in their study also reported a relationship between quality of worklife and organization culture, employees' job satisfaction. Malik, Cao, Mughal, Kundi, Mughal, \& Ramayah (2020) contend that if top management ensures their commitments and meets the employee's expectations, this might reinforce the employee's good judgment for trust and fairness in their organization and thus it results in a positive psychological contract between the employer and the employee.

Kanten and Sadullah (2012) also discussed the relationship between quality of work-life and individual work performance, organizational culture through the application of the theory of Quinn and Spreitzer membership relationship. Zeqiri and Alija (2016) examined the perceived organizational culture and its influence on the employee's performance concerning the quality of work-life, yet they reported a weak relationship. Parent \& Lovelace (2018) studied the connections between employee performance, organizational culture, and an individual's ability to adapt to ongoing organizational change, whereas Razak, Ma'amor, \& Hassan (2016) have reported that there is a relationship between organizational culture and employee quality of work-life and has a positive effect on the individual's performance.

Based on the well-documented relations between qualities of work-life, individual work performance, and organization culture, below two hypotheses, have been proposed (Acar \& Acar, 2014).

$\mathrm{H}_{1}$ : Organizational Culture has a significant moderating effect upon relation \& cooperation and individual work performance.

$\mathrm{H}_{2}$ : There is a positive significant moderating impact of organizational culture upon facilities provided at the workplace and individual work performance.

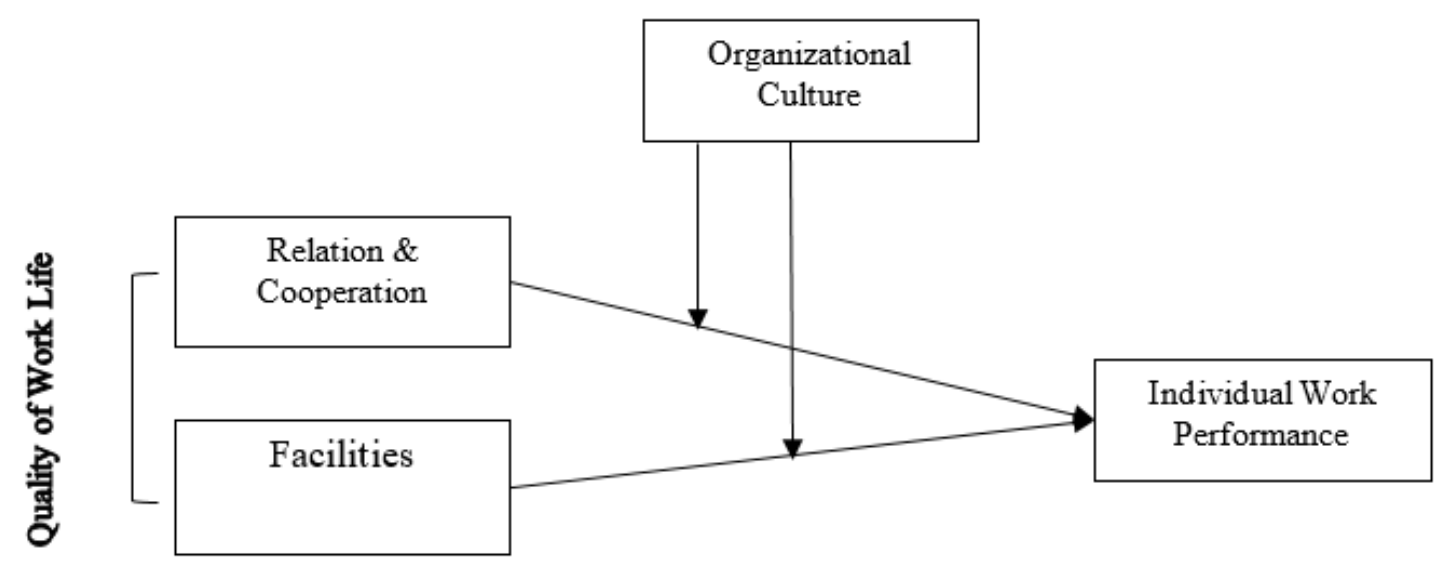

Figure1. Framework of the study based on Literature Review. 


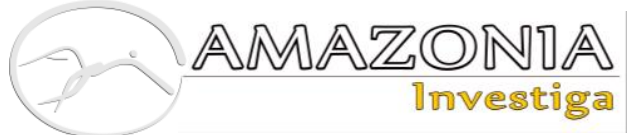

\section{Research Methods}

This study is explanatory, so a cross-sectional quantitative research design was adopted. Nonprobability convenience sampling technique was used to collect through a structured. Since the population was big, therefore, Krejcie and Morgan's (1970) table was sued to select the sample size i.e., 400.

\section{Measures}

The entire instrument was adopted in this study. The quality of the work-life scale was adopted from Swamy, Nanjundeswara, \& Srinivas (2015). It has 10 items measured on a five-point Likert scale. Five items for relation and cooperation and five for

facilities. Similarly, the instrument for organizational culture was adapted from Lund (2003). All the items ranged from 1 (strongly disagree) to 5 (strongly agree). Likewise, the scale of individual work performance was adopted from Koopman et al. (2011), all its items ranged from 1 (strongly disagree) to 5 (strongly agree).

\section{Results and Discussion}

SPSS 25 was employed for data analysis. Descriptive statistics and inferential statistics including process file version 3 of Andrew, F. Hayes were also used for the analysis of moderation results. Cronbach alpha was used to check the reliability of the scale while hierarchical multiple regressions were used to test the hypotheses.

Table 1.

Demographic Information.

\begin{tabular}{llll}
\hline Variable & Characteristics & n & Percentage \\
\hline \multirow{2}{*}{ Sector } & Public & 208 & 52 \\
& Private & 192 & 48 \\
\multirow{2}{*}{ Education } & Master & 187 & 46.75 \\
& M. Phil & 142 & 35.5 \\
& PhD & 71 & 17.75 \\
\multirow{2}{*}{ Designation } & Medical Superintendent & 139 & 34.75 \\
& Assistant Director & 115 & 28.75 \\
& Deputy Director & 78 & 19.5 \\
Gender & Director & 68 & 17 \\
& Male & 250 & 62.5 \\
\hline
\end{tabular}

Source: Primary Data Survey.

Analysis of the demographic characteristics of the sample respondents in table 1 reveals that 208 $(52 \%)$ were male respondents who participated in the survey while 192 (48\%) were women. Moreover, 187 (46.75) respondents were having master's degrees while $142(35.5 \%)$ were having MPhil degrees and $71(17.75 \%)$ respondents were holding doctoral degrees. This explains that the majority of respondents working in health organizations are young and having masters and
MPhil degrees. Furthermore, regarding designation, the majority of the respondents 139 $(34.75 \%)$ were medical superintendents, followed by assistant directors i.e., 115 $(28.75 \%)$, deputy directors $78(19.5 \%)$, and directors $68(17 \%)$ out of a total of 400 respondents. The total $250 \quad(62.5 \%)$ male respondents who participated in the study were $250(62.5 \%)$ while $150(37.5 \%)$ were female.

Table 2.

Reliability Analysis.

\begin{tabular}{llll}
\hline Variables & No of Items & Items Deleted & Cronbach Alpha \\
\hline Relation Cooperate & 5 & 0 & 0.815 \\
Facilities & 5 & 0 & 0.798 \\
Overall Individual Performance & 20 & 3 & 0.800 \\
Organization Culture & 8 & 0 & 0.815 \\
\hline
\end{tabular}

Source: Primary Data Survey 
Table 2 reports the results for Cronbach alpha, the alpha score for relationship and cooperation was 0.815 as could be seen in column 4 , and for facilities, it was reported 0.798 . The Cronbach alpha for individual work performance was
0.800 , and for organizational culture, it was 0.815 . Since all values were above the minimum threshold value, therefore, it was decided that the instrument has the internal consistency and reliability to measure the responses.

Table 3.

Moderating Effect of Organizational Culture between Relation and Cooperation, and Individual Work Performance.

\begin{tabular}{llllllllll}
\hline D.V & I.V & $\mathbf{R}$ & $\mathbf{R}^{\mathbf{2}}$ & $\mathbf{F}$ & $\mathbf{T}$ & $\boldsymbol{\beta}$ & $\mathbf{p}$ & LLCI & ULCI \\
\hline IWP & CONSTANT & 0.7263 & 0.527 & 110.14 & 80.19 & 2.98 & 0.000 & & \\
& RC & & & & 5.80 & 0.276 & 0.000 & & \\
& OC & & & & 8.38 & 0.291 & 0.000 & & \\
& RC*OC & & & & 2.30 & 0.091 & 0.021 & 0.0134 & 0.1698 \\
& $\Delta \mathbf{F}$ & & & 5.314 & & & 0.0218 & & \\
& $\Delta \mathbf{R}^{2}$ & & 0.0085 & & & & & & \\
\hline
\end{tabular}

Source: Survey Data

Table-3 shows moderating results for organizational culture, relation and cooperation, and individual work performance. Hayes process file version 3 and model 1 for moderation were used. The result shows that before adding organizational culture as moderator $\mathrm{R} 2=0.527$, $52.7 \%$ variance was shown upon individual work performance by relation and cooperation with the goodness of fit $\mathrm{F}=110.14, \mathrm{p}<0.05$. Yet, after adding organizational culture as a moderator in the regression equation $\Delta \mathrm{R} 2=0.0085$, mean $0.85 \%$ variance was shown and $\Delta \mathrm{F}=5.314$, $\mathrm{p}<0.05$, there was no zero between lower limit confidence interval and upper limit confidence interval and beta value of relation and cooperation upon IWP $\beta=0.276, \quad \mathrm{p}<0.01$ explained that $27.6 \%$ change could be observed in IWP due to 1 percent change in relation and cooperation, While organizational culture $\beta=0.291, p<0.01$, it means one percent change in organizational culture could bring $29.1 \%$ change in IWP, while interaction term $\beta=0.091, p<0.05$ means that $9.1 \%$ variation could be seen in IWP and it is significant due to interaction term. Therefore, it is evident that there is a significant moderating effect as could be seen in table 3, thus, H1 is accepted.

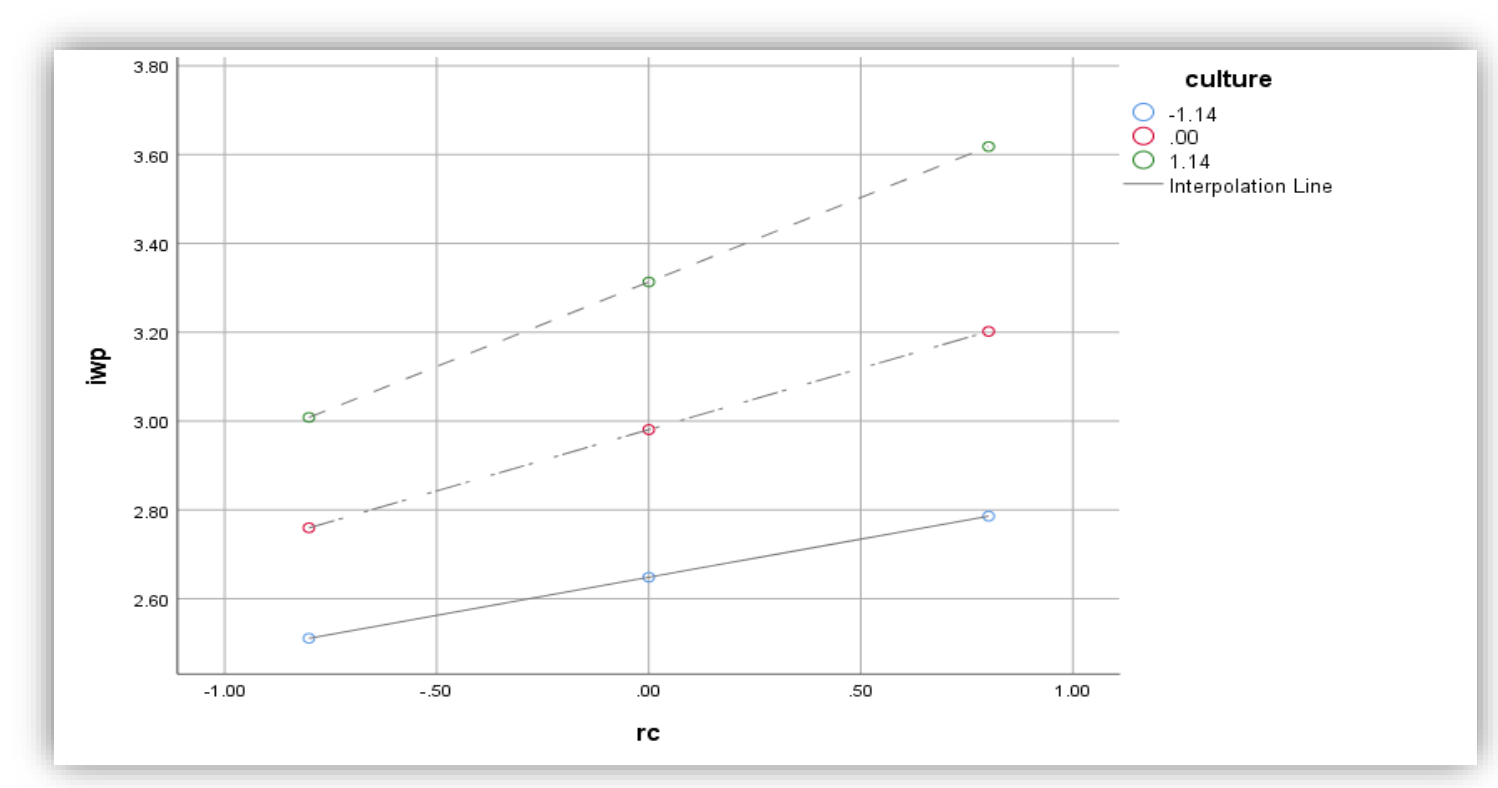

Figure 2. Moderation Graph RC, Culture, IWP, Source: Survey Data. 


\section{AMAZONDA \\ Investiga}

The moderation graph was plotted one standard deviation above and below the mean, the blue line shows a low level of organizational culture moderating effect, the red line moderate, and the green line shows the high moderating effect of organizational culture. The green, blue, and red lines are going upward from left to right, this explained that low, high, and moderate levels of supportive culture could increase the relationship

Table 4.

Moderating Effect of Organizational Culture between facilities and individual work performance.

\begin{tabular}{llllllllll}
\hline D.V & I.V & $\mathbf{R}$ & $\mathbf{R 2}$ & $\mathbf{F}$ & $\mathbf{T}$ & $\boldsymbol{\beta}$ & $\mathbf{p}$ & LLCI & ULCI \\
\hline IWP & CONSTANT & 0.7234 & 0.523 & 144.88 & 103.14 & 2.87 & 0.000 & & \\
& Facilities & & & & 5.97 & 0.205 & 0.000 & & \\
& OC & & & & 12.14 & 0.329 & 0.000 & & \\
& F*OC & & & & 4.65 & 0.132 & 0.000 & 0.0766 & 0.1888 \\
& $\Delta \mathbf{F}$ & & & 21.62 & & & & & \\
& $\Delta \mathbf{R 2}$ & & 0.026 & & & & & & \\
\hline
\end{tabular}

Source: Survey Data

Table 4 highlights moderating results for organizational culture, facilities, and individual work performance. Again, Hayes process file version 3 and model 1 were used for moderation analysis. Results indicate that before adding organizational culture as moderator $\mathrm{R} 2=0.523$, $52.3 \%$ variance was shown upon individual work performance, facilities, and the value for the goodness of fit was $\mathrm{F}=144.88, \mathrm{p}<0.05$, but by adding organizational culture as a moderator in the regression equation $\Delta \mathrm{R} 2=0.026$, mean $0.2 .6 \%$ variance was shown and $\Delta \mathrm{F}=21.62$, $\mathrm{p}<0.05$, there was no zero between lower limit between relationship and cooperation and individual work performance. By providing a supportive culture, better work performance results will be the outcome, a more productive workforce, and better individual work performance. This means that three levels of culture help in enhancing the relationship and cooperation, and individual work performance in healthcare organizations.

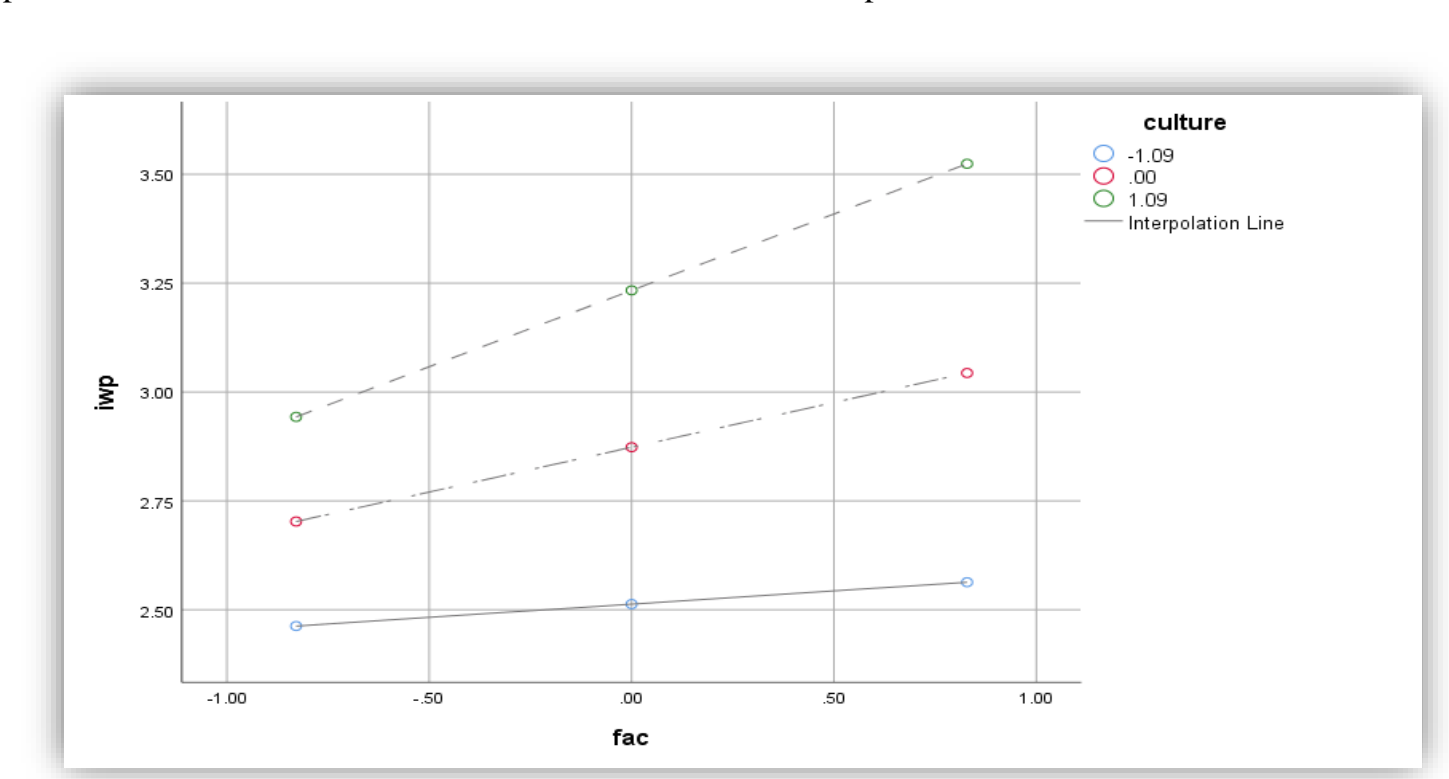

Figure 31. Moderation Graph Facilities, OC \& IWP, Source: Survey Data.

confidence interval and upper limit confidence interval and beta value of facilities upon IWP $\beta=$ $0.205, \mathrm{p}<0.01$ explain that $20.5 \%$ significant change could be observed in IWP due to 1 percent change in facilities. While organizational culture $\beta=0.329, p<0.01$ means that one percent change in organizational culture could bring $32.9 \%$ change in IWP, while interaction term $\beta=$ $0.132, \mathrm{p}<0.05$ means that $13.2 \%$ variation could be seen in IWP, and it is significant due to interaction term. Therefore, table 4 reports a significant moderating effect, thus $\mathrm{H} 2$ is accepted. 
Organizational culture significantly moderated the relationship between facilities provided at the workplace to health professionals' which ultimately enhanced the performance. The moderating effect took place one standard deviation below the mean. It means that increase in the facilities to professionals will increase the performance and vice versa. Green line has higher steeper as compared to red and blue lines, which shows that a high level of care and facilities could result in high productivity and performance.

The purpose of adding the moderator was to strengthen the weak relationship among predictors and the criterion as reported in the previous studies by Kwahar \& Iyortsuun (2018). Organizational culture provides significant moderating results between relationship and cooperation, and facilities. The findings of this study are consistent with Zeqiri \& Alija (2016) who reported a significant relationship among predictors and criterion variables. Likewise, Acar \& Acar (2014) reported a significant moderating impact of organizational culture upon the quality of work-life and individual work performance in healthcare organizations. Similarly, Wahlberg, Ramalho, \& Brochado (2017) also supported the results that development, supportive, and innovative culture enhances the quality of worklife and individual work performance of healthcare staff in healthcare organizations.

\section{Conclusions}

Based on the literature reviews and findings of the study, it is concluded this model will help the management of healthcare institutions to use the results of this study with moderating effects of organizational culture on the relationship between QWL and IWP as a mean of developing as an understanding and management relationship. This study adds is an effort to test the variables of QWL, IWP and OC found in the literature to suggest a steadiness between QWL and IWP. The connecting of these three variables into a single construct is an expansion in the theoretical comprehension and knowledge of QWL, IQP and OC. It will nurture a better relationship and will contribute to the inclusive performance and experience. This study is new in the context of health sector organization in developing countries, earlier such study has not been conducted in developing countries in the sub-continent. Thus, study further concluded that there is an intense need to improve the quality of work-life and workplace of health professionals so that employees deliver their best and help organizations to achieve their objectives. Also, there is a need to establish and highlight the supportive culture at the workplace because culture plays a very important role in bringing the desired level of performance in the employees which ultimately leads the organization to success.

\section{Bibliographic references}

Acar, A.Z. \& Acar, P. (2014) Organizational culture types and their effects on organizational performance in Turkish hospitals. EMAJ: Emerging Markets Journal, 3, 18-31.

Akhtar, R., Nazarudin, M.N., \& Kundi, G.M. (2021a). Empirical evidence on the mediating role of job satisfaction, commitment, trust in leadership, intention to leave between leadership styles, performance appraisal, and physical education teacher's performance. Psychology and Education, 58(4), 729- 38.

Akhtar, R., Nazarudin, M.N., \& Kundi, G.M. (2021b). Reversing the paradigm: Empirical evidence of followership in shaping transactional leadership style: The mediating effect of trust, leader-member exchange (LMX). Psychology and Education, 58(5), 422- 433.

Albejaidi, F., Kundi, G.M., \& Mughal, Y.H. (2020). Decision-making, leadership styles and leadership effectiveness: An AMOSSEM approach. African Journal of Hospitality, Tourism and Leisure, 9(1), 1-15.

Allworth, E., \& Hesketh, B. (1999). Constructoriented biodata: capturing change related and contextually relevant future performance. International Journal of Selection and Assessment, 7(2), 97-111.

Almalki, M.J, Fitzgerald, G., \& Clark, M. (2012). Quality of work life among primary health care nurses in the Jazan region, Saudi Arabia: A cross-sectional study. Hum Resource Health, 10(1), 30.

Ashford, S. J. (1986). Feedback seeking in individual adaptation: A resources perspective. Academy of Management Journal, 29, 465-487.

Asmui, M., Hussin, A., \& Paino, H. (2012). The importance of work environment facilities. International Journal of Learning and Development, 2, 289-298.

Attride-Stirling, J. (2001). Thematic networks: An analytic tool for qualitative research. Qualitative Research, 1(3), 385-405.

Awadh, A.M., \& Saad, A.M. (2013). Impact of Organizational Culture on Employee Performance. International Review of Management and Business Research, 2(1), 168-175. 


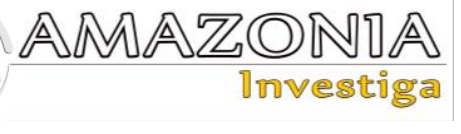

Awan, K.Z., Qureshi, W., Akram, M., Shahzad, K. (2014). Mediation role of organizational commitment in the relationships of organizational politics and job involvement and employee performance. International Journal of Academic Research in Economics Management Science, 3(6), $1-21$.

Azril, M. S., Jegak, U., Asiah, M., Azman, A. N., Bahaman, A. S., Jamilah, O., \& Thomas, K. (2010). Can quality of work life affect work performance among government agriculture extension officers: A case from Malaysia. Journal of Social Sciences, 6(1), 64-73.

Babalola, O., Gbadegesin, A., \& Patience, E. (2014). A Study of Superior-Subordinate Relationship and Employees' Commitment to the Core Beliefs of Organization in Public Universities of Southwest, Nigeria. American Journal of Business and Management, 3(1), 28-38

Bligh, M. (2017). Leadership and Trust. In Leadership today (pp. 21-42). Cham: Springer, 10.1007/978-3-319-31036-7_2.

Busari, A.H., Khan, S.N., Abdullah, S.M., \& Mughal, Y.H. (2019). Transformational leadership style, followership, and factors of employees' reactions towards organizational change. Journal of Asia Business Studies, 14(2), 181-209.

Cropanzano, R., Anthony, E., Daniels, S., \& Hall, A. (2017). Social Exchange Theory: A Critical Review with Theoretical Remedies. The Academy of Management Annals, 11, $1-38$.

Daubermann, D. \& Tonete, V. (2011). Quality of work life of nurses in primary health care. Acta Paulista de Enfermagem, 25, 277-283.

Deb, T. (2006). Strategic approach to human resource management: Concepts, tools, and applications. $7^{\text {th }}$ Ed. New Delhi: Atlantic Publishers and Distributors.

Fay, D., \& Sonnentag, S. (2009). A Look Back to Move Ahead: New Directions for Research on Proactive Performance and Other Discretionary Work Behaviours. Applied Psychology, 59, 1-20. 10.1111/j.14640597.2009.00413.x

Gatseliuk, V., Strelbitska, L., Herasymchuk, O., Pavlyshyn, A., \& Khrystiuk, V. (2021). The influence of religion on the norms of criminal law and process: an internationalcomparative study. Amazonia Investiga, 10(42), 226-235. https://doi.org/10.34069/AI/2021.42.06.21

Glasser, B. G., \& Strauss, A. L. (1967). The discovery of grounded theory: Strategies for qualitative research. Chicago: Aldine.
Hofstede, G. (1997). Culture and organizations: Software of the mind. New York: McGrawHill. Pp, 123124.

Hsu, M. Y., \& Kernohan, G. (2006). Dimensions of hospital nurses' quality of working life. Journal of Advanced Nursing, 54, 120-131.

Kanten, S., \& Sadullah, M. (2012). Empirical research on relationship quality of work life and work engagement. Procedia - Social and Behavioral Sciences, 62, 360-366.

Koopmans, L., Bernaards, C.M., Hildebrandt, V.H., Schaufeli, W.B., de Vet Henrica, C.W., \& van der Beek, A.J. (2011). Conceptual frameworks of individual work performance: a systematic review. Journal of Occupation and Environmental Medicines, 53(8), 856-66.

Krejcie, R.V., \& Morgan, D.W. (1970) Determining Sample Size for Research Activities. Educational and Psychological Measurement, 30, 607-610.

Kwahar, N., \& Akuraun, S. (2018). Determining the underlying dimensions of quality of work life (QWL) in the Nigerian hotel industry. Entrepreneurial Business and Economics Review, 6(1), 53-70.

Lennox, R.D., \& Mansfield, A.J. (2001). A latent variable model of evidence-based quality improvement for substance abuse treatment. The Journal of Behavioral Health Services \& Research, 28(2), 164-176.

Lund, D.B. (2003). Organizational Culture and Job Satisfaction. Journal of Business \& Industrial Marketing, 18(3), 219-236.

Malik, S.Y., Cao, Y. Mughal, H.Y., Kundi, G.M., Mughal, M.H., Ramayah, T. R. (2020). Pathways towards sustainability in organizations: Empirical evidence on the role of green human resource management practices and green intellectual capital. Sustainability (MDPI), 12(8), 1-24,

Parent, J.D., \& Lovelace, K.J. (2018). Employee engagement, positive organizational culture, and individual adaptability. On the Horizon, 26(3), 206-214.

Razak, NA., Ma'amor, H. \& Hassan, N. (2016). Measuring reliability and validity instruments of work environment towards quality work life. Procedia Economics and Finance, 37, 520-528.

Ritchie, J., \& Spencer, L. (1994). Qualitative Data Analysis for Applied Policy Research. London: Routledge:

Ruzevicius, J. (2012). Management de la qualite. Notion globale et recherche en la matiere. Access from: https://www.researchgate.net/publication/28 1372752_Quality_of_Life_and_of_Working _Life_Conceptions_and_Research 
Sirgy, M.J., Efraty, D., Siegel, P., \& Lee, D.J. (2001). A new measure of the quality of work-life (QWL) is based on need satisfaction and spillover theory. Social Indicator Research, 55, 241-302.

Swamy, D.R. Nanjundeswaraswamy, T. S., \& Srinivas, R.S. (2015). Quality of Work Life: Scale Development and Validation. International Journal of Caring Sciences, 8(2), 281-298.

Taher, A.M. (2013). Variations of quality of work-life of academic professionals in Bangladesh. European Journal of Training and Development, 37(6), 580-595.

Valizadeh, A., \& Ghahremani, J. (2012). The relationship between organizational culture and quality of working life of employees. European Journal of Experimental Biology, 2 (5), 1722-1727.
Wahlberg, T.A., Ramalho, N., \& Brochado, A. (2017). Quality of working life and engagement in hostels. Tourism Review, 72(4), 411-428.

Warrick, D.D. (2017). What leaders need to know about organizational culture? Business Horizons, 60(3), 395-404.

Zare, H., Haghgooyan, Z., \& Asl, Z. K. (2012). Determining and prioritizing the criteria and scales of Quality of Work Life (QWF) by AHP Method. European Journal of Social Sciences, 27(3), 346-359

Zeqiri, J., \& Alija, S. (2016). The Organizational Culture Dimensions: The Case of an Independent Private University in Macedonia. Babe-Bolyai University of Economics, 61, 20-31. 